\title{
An Analysis of the Role of Cultural Tourism on Regional Development of the North Central Province of Sri Lanka
}

\author{
By \\ Hetti Arachchige Nishantha Hettiarachchi \\ Registered Number GS/PhD/Geo/3660/08 \\ (1052 SS 2008 001)
}

Thesis submitted to the University of Sri Jayewardenepura for the award of the Degree of Doctor of Philosophy in Geography

On $30^{\text {th }}$ October 2013 


\section{DECLARATION BY THE CANDIDATE}

The work described in this thesis was carried out by me under the supervision of Professor (Emeritus) Mrs. Y.A.D.S. Wanasinghe, and Co-supervisor, Professor Mrs. T.M.S.P.K. Tennakoon, Department of Geography, University of Sri Jayewardenepura. This thesis has never been submitted in whole or in part to any University for a Degree or a Diploma.

\section{(2)}

H.A.N. Hettiarachchi,

Department of Geography,

University of Sri Jayewardenepura,

Gangodawila,

Nugegoda.

Date.05:06.2014 


\section{DECLARATION BY SUPERVISORS}

We certify that the above statement made by the candidate is true and that this thesis is suitable for submission to the University for the conferment of the $\mathrm{PhD}$ Degree.

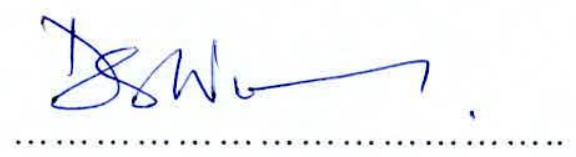

Professor Emeritus (Mrs.) Y.A.D.S. Wanasinghe

Supervisor,

Department of Geography,

University of Sri Jayewardenepura,

Gangodawila,

Nugegoda.

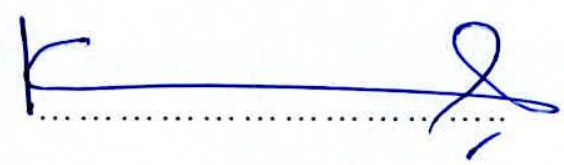

Professor (Mrs.) T.M.S.P.K. Tennakoon,

Co-supervisor,

Department of Geography,

University of Sri Jayewardenepura,

Gangodawila,

Nugegoda. 


\section{TABLE OF CONTENT}

\section{Content}

I. Table of Contents

II. List of Tables

III. List of Figures

IV. Abbreviations

IV. Acknowledgment

V. Abstract
Page Number

I-IV

V-VII

VII-XI

XII-XIII

XIV-XVI

XVII-XVIII

CHAPTER ONE - Introduction

01-31

1.1. Background of the Study

01-06

1.2. Significance of the Study

06-10

1.3. Objective of the Study

1.4. Methodology

12-28

1.5. Limitation of the Study

28-30

1.6. Outline of the Thesis

30-31

CHAPTER TWO - Literature Review

32-129

2.1. Introduction

2.2. Introduction to Cultural Tourism 
2.2.2. Attributes of Cultural Tourist Attractions and Destinations

2.2.3. Cultural Tourist

2.2.4. Approaches to the Study of Cultural Tourism as a Discipline

2.2.5. Reasons for the Popularity of Cultural Tourism

2.2.6. Subsets of Cultural Tourism

2.3. Cultural Tourism and Regional Development

2.4. Theoretical Background of Regional Development and Cultural Tourism

2.5. Problems of Cultural Tourism and Regional Development

2.6. Regional Development and its Objectives

2.7. Regional Development Disparities in Sri Lanka

$108-110$

2.8. Regional Development Approaches in Sri Lanka

CHAPTER THREE - The Study Area: Salient Features of the North Central Province

3.1. Introduction

$130-133$

3.2. Location and the Geographical Setting of the North Central Province

3.3. Development Disparities in the North Central Province

3.4. Socio Economic Back Ground and Intra Regional Disparities of the North Central Province

3.4.1. Demographic Characteristics 
3.4.3. Housing Conditions

$175-176$

3.4.4. Employment and Sources of Income

$176-181$

3.4.5. Employment

$182-183$

3.4.6. Education

183-184

3.4.7. Infrastructure Facilities

184-191

CHAPTER FOUR - Cultural Tourism of the North Central Province:

\section{Resources and the Potential}

$192-274$

4.1. Introduction

$192-193$

4.2. Cultural Tourist Attractions of the North Central Province

193

4.2.1. Cultural Tourist Attractions Related to History and Archeology

$193-220$

4.2.2. Cultural Tourist Attractions Related to Lifestyles and Rituals

220-225

4.2.3. Cultural Tourist Attractions Related to Agriculture

225-230

4.2.4. Cultural Tourist Attractions Related to Irrigation

4.2.5. Cultural Tourist Attractions Related to Traditional Livelihoods

4.2.6. Cultural Tourist Attractions Related to Customs, Traditions and Folklore

4.3. Tourist Arrivals to the North Central Province

4.4. Constraints Related to Cultural Tourism of the North Central Province

4.4.1. The Problems Created to the Region

4.4.2 The Constraints Faced by Tourists in the Region

4.4.3 The problems faced by the village folk and the business community 
4.5. Possible Devices Strategies to Mitigate the Identified Problems

4.6. Institutional Background Related to Cultural Tourism of the NCP

4.6.1. The Role of Travel Agencies in Promoting Cultural Tourism of the NCP

CHAPTER FIVE - The Contribution of Cultural Tourism for the Development of the North Central Province

$\begin{array}{ll}\text { 5.1. Introduction } & \mathbf{2 7 6}\end{array}$

5.2. The Role of Cultural Tourism on Regional Development of the NCP 277

5.2.1. Generation of Employment Opportunities and Sources of Income

5.2.2. Agriculture and Livelihood Development

5.2.3 Empowerment of Women

5.2.4. Multiplier Effects of Cultural Tourism

5.2.5. Infrastructure Development

5.2.6 Development of Small and Medium Scale Industries 


\section{LIST OF TABLES}

List of Tables

Page Number

Table 1.1. Selected Sample for the In-depth Study 17-18

Table 1.2. Distribution of the Sample within Four Categories

Table 1.3. Target User Groups for Interview, Discussions and Case Studies

Table 2.1. Activity Based Cultural Tourists Typology

Table 2.2. Village-origin Staff in the Dai Village Company in China - 2010

Table 3.1. Mean and Annual and Monthly Rainfall Distribution of the NCP $2005-2010$

Table 3.2. Mean and Annual and Monthly Temperature Distribution of the NCP - 2006-2010

Table 3.3. Human Development Index and Dimensions of Sri Lanka by District - 2012

Table 3.4. Provincial Gross Domestic Production - 2010 - 2011.

Table 3.5. Composition of Sectoral Provincial Gross Domestic Production $-2010-2011$

Table 3.6. Mean and Median Household Income (in Rs.) by Province and District -2010-2011

Table 3.7. Income Poverty, Multidimensional Poverty Index and Multi Dimensionally Poverty Headcount - 2009-2010

Table 3.8. Labour Force Participation Rate by Gender and District - 2011 
Table 3.9. Percentage Distribution of Employed Population by Major Industry Groups by District - 2011

Table 3.10. Ethnic Composition of the Selected Divisional Secretariat Divisions - 2012

Table 3.11. Extent of Paddy Lands, Number of Farmers and Average Yield of Paddy by Divisional Secretariat Divisions- 2012

Table 3.12. Information of Animal Husbandry of the DSD Level - 2012

Table 3.13. Number of Schools and Students -2012

Table 3.14. Sources of Obtaining Drinking Water - 2012

Table 4.1. Number of Tourist Who Visited the Anuradhapura Historic City

Table 4.2. Number of Tourists Visited the Attractions of Mihintale

Table 4.3. Number of Tourist Visited the Folk Museum and Revenue from Sales of Tickets $2008-2012$

Table 4.4. Number of Tourists According to Age

Table 4.5. Goals and Ambitions of the Tourists

Table 4.6. Sources of Information on Places of Interest

Table 4.7. Modes of Garbage Disposal

Table 4.8. Problems Faced by Tourists within the Cultural Attractions of the NCP

Table 5.1. Composition of the Employment Related to Cultural Tourism by DSD Level

Table 5.2. Nature of Employment Related to Cultural Tourism

Table 5.3. Collection Modes of Selling Items of the Small Scale Business Community

Table 5.4. Time Duration of Employees Engage in Cultural Tourism 
Table 5.5. Monthly Income Levels of the Small Scale Business Community

Table 5.6. Monthly Personal Savings of the Business Community Engaged in Cultural Tourism

Table 5.7. Miscellaneous Items Sold by the Regional Business Community

Table 5.8. Women Engaged in Cultural Tourism Employments

Table 5.9. Secondary Sources of Investment of the Business Community

Table 5.10. Items Purchased by the Business Community from Cultural Tourism

Table 5.11. Number of Guest Nights in Graded Accommodation in the $\mathrm{NCP}-2001-2012$

Table 5.12. Use of Internet Information by Foreign Tourists

Table 5.13. Nature of Small and Medium Scale Industries Related to Cultural Tourism of the NCP

\section{LIST OF FIGURES}

\section{List of Figures}

Figure 1.1. Location of the Study Area

Figure 1.2. Distribution of the Sample among Research Sites

Figure 2.1. Gunn's Model of a Cultural Tourist Attraction

Figure 2.2. Canter's Model Applied to a Cultural Tourist Attraction

Figure 2.3. Cultural Tourist Typology Based on Decision to Visit Destination

Figure 2. 4. Links between Cultural Tourism and Regional Development

Figure 3.1. The Relative Location of the North Central Province 
$\begin{array}{lll}\text { Figure 3.2. Districts Vulnerable to Drought } & \mathbf{1 4 0}\end{array}$

$\begin{array}{lll}\text { Figure 3.3. The Drainage Basins of the NCP } & 144\end{array}$

Figure 3.4. Mean and Median Monthly Per Capita Income by Sector, Province and Districts - 2010/11 152

Figure 3.5. Multidimensional Poverty Headcount Index - $2012 \quad 156$

Figure 3.6. Poverty Headcount Index by Province - 2006/07 and 2009/10 157

Figure 3.7. Provincial Road Density of Sri Lanka - $2011 \quad 158$

Figure 3.8. Provincial Contribution of Agriculture and Service Sectors to the Total Employment - 2011 162

Figure 3.9. Provincial Unemployment Rate of Sri Lanka - 2011 164

Figure 3.10. Population of the Selected Divisional Secretariat Divisions 2012

Figure 3.11. Population Distribution According to Religion-2012 170

Figure 3.12. Population Density of the Study Area - 2013 172

Figure 3.13. Housing Conditions of the Selected Divisional Secretariat $\begin{array}{ll}\text { Divisions - } 2012 & 175\end{array}$

Figure 3.14. Extent of Land and Number of Farmers under Chena Cultivation $-2012$

Figure 3.15. DSD Level Employment Details of the NCP-2012 182

$\begin{array}{lll}\text { Figure 3.16. Health Facilities of the Selected DSDs - } 2012 & 187\end{array}$

Figure 3.17. Availability of Sanitary Facilities - $2012 \quad 189$

Figure 4.1. Panoramic View of Anuradhapura Historic City 196

Figure 4.2. The Environs of the Historic City with the Tanks 197

$\begin{array}{lll}\text { Figure 4.3. The Sri Maha Bodhiya, Festival and Ceremonies } & 199\end{array}$ 
$\begin{array}{lll}\text { Figure 4.5. Thuparamaya and Lovamahapaya } & \mathbf{2 0 2}\end{array}$

Figure 4.6. Abhayagiri Dagaba and Jetavanaramaya 203

$\begin{array}{lll}\text { Figure 4.7. Mirisavetiya Stupa } & 204\end{array}$

$\begin{array}{lll}\text { Figure 4.8. Isurumuniya } & \mathbf{2 0 5}\end{array}$

Figure 4.9. Kuttam Pokuna (The Twin Pond) 206

$\begin{array}{lll}\text { Figure 4.10. The Environs of Mihintale } & 209\end{array}$

Figure 4.11. Ancient Ponds in the Vicinity of Mihintale 212

$\begin{array}{lll}\text { Figure 4.12. Places of Attractions at Tantirimale } & \mathbf{2 1 5}\end{array}$

Figure 4.13. Number of Tourist Visited Tantirimale 216

$\begin{array}{lll}\text { Figure 4.14. Anuradhapura and Abhayagiri Archaeological Museums } & \mathbf{2 1 8}\end{array}$

$\begin{array}{lll}\text { Figure 4.15. Anuradhapura Folk Museum } & \mathbf{2 1 9}\end{array}$

Figure 4.16. Picturesque View of a Traditional Tank Village in the NCP 222

Figure 4.17. Components of a Traditional Tank Village in the NCP 223

Figure 4.18. Foreign Tourists at the Villages of NCP 225

Figure 4.19. Foreign Tourists Visit Chena Cultivation at Tantirimale 227

$\begin{array}{lll}\text { Figure 4.20. } & \text { Kiri Ithuruma } & \mathbf{2 2 8}\end{array}$

Figure 4.21. Maiden Rice Ceremony at Anuradhapura 230

$\begin{array}{lll}\text { Figure 4.22. Pottery Making in the NCP } & 233\end{array}$

Figure 4.23. Using Buffalos in Threshing 234

Figure 4.24. Inland Fishing Practices in the NCP 235

$\begin{array}{lll}\text { Figure 4.25. Performance of a Gammadu Festival } & 237\end{array}$ 
Figure 4.26. Arrivals of Tourists to the NCP - 2000-2011

Figure 4.27. Number of Foreign Tourists to the NCP by Countries

Figure 4.28. Gender Composition of Tourist - 2011 - 2013.

Figure 4.29. Percentage Distribution of Modes of Transport Used by Tourists

Figure 4.30. Number of Guest Nights in Graded Accommodation Establishments of the NCP - 2000-2011

Figure 4.31. Tourists' Satisfactory Level about the Visits to NCP

Figure 4.32. Unsystematic Garbage Disposal at the Sacred City of Mihintale

Figure 4.33. Using Archeological Monuments as Supportive Structures and Erection of Tents Covering Them

Figure 4.34. Uncouth Behaviors of Domestic Tourists

Figure 4.35. Unauthorized Constructions in the Tourist Sites of the NCP

Figure 4.36. Number of Tourists and the Accommodation Capacity 2001 2011

Figure 4.37. Inadequacy of Accommodation Facilities for Domestic Tourists

Figure 4.38. Quotidian Number of Tourist Visit to the NCP

Figure 4.39. Community Service by the Commercial Enterprises

Figure 4.40. Alternative Ways Introduced for Proper Disposal of Garbage

Figure 4.41. Tour Guide Training Programmes by SLITHM

Figure 5.1. Nature of Employments Related to Cultural Tourism - 2011

Figure 5.2. Pavement Hawkers in Mihintale

Figure 5.3. Palm Readers and Snake-charmers in the Historic City of Anuradhapura

Figure 5.4. Number of Employees in Hotel and Accommodation Sector 
Figure 5.5. Modes of Marketing of Small Scale Trading Community

Figure 5.6. Business Community in the Sacred City of Mihintale

Figure 5.7. Regional Brokers to the NCP by Direction of Approach

Figure 5.8. Number of Migrants and Their Places of Birth

Figure 5.9. Wayside Business Community Engaged in Cultural Tourism

Figure 5.10. Fishermen Engaged in Fish Selling

Figure 5.11. Number of Foreign Tourists Visited the Traditional Villages of the NCP

Figure 5.12. Women Engaged in Business Activities

Figure 5.13. Various Multipliers of Cultural Tourism of the NCP

Figure 5.14. Secondary Sources of Income of the Business Community of Cultural Tourism

Figure 5.15. Indirect Employments of Cultural Tourism

Figure 5.16. Infrastructure Development of Tourist Attractions

Figure 5.17. Amelioration of Public Sanitation Facilities of the NCP

Figure 5.18. Contribution of Cultural Tourism on Social Infrastructure Development

Figure 5.19. Number of Rooms in Graded Tourist Hotels of the NCP - 2000 2012

Figure 5.20. Foreign Tourists Participating in Traditional Food Processing Systems

Figure 5.21. Cottage Industries Related to Cultural Tourism

Figure 5.22. The Advantages of Prevalence in Small and Medium Scale Industries 


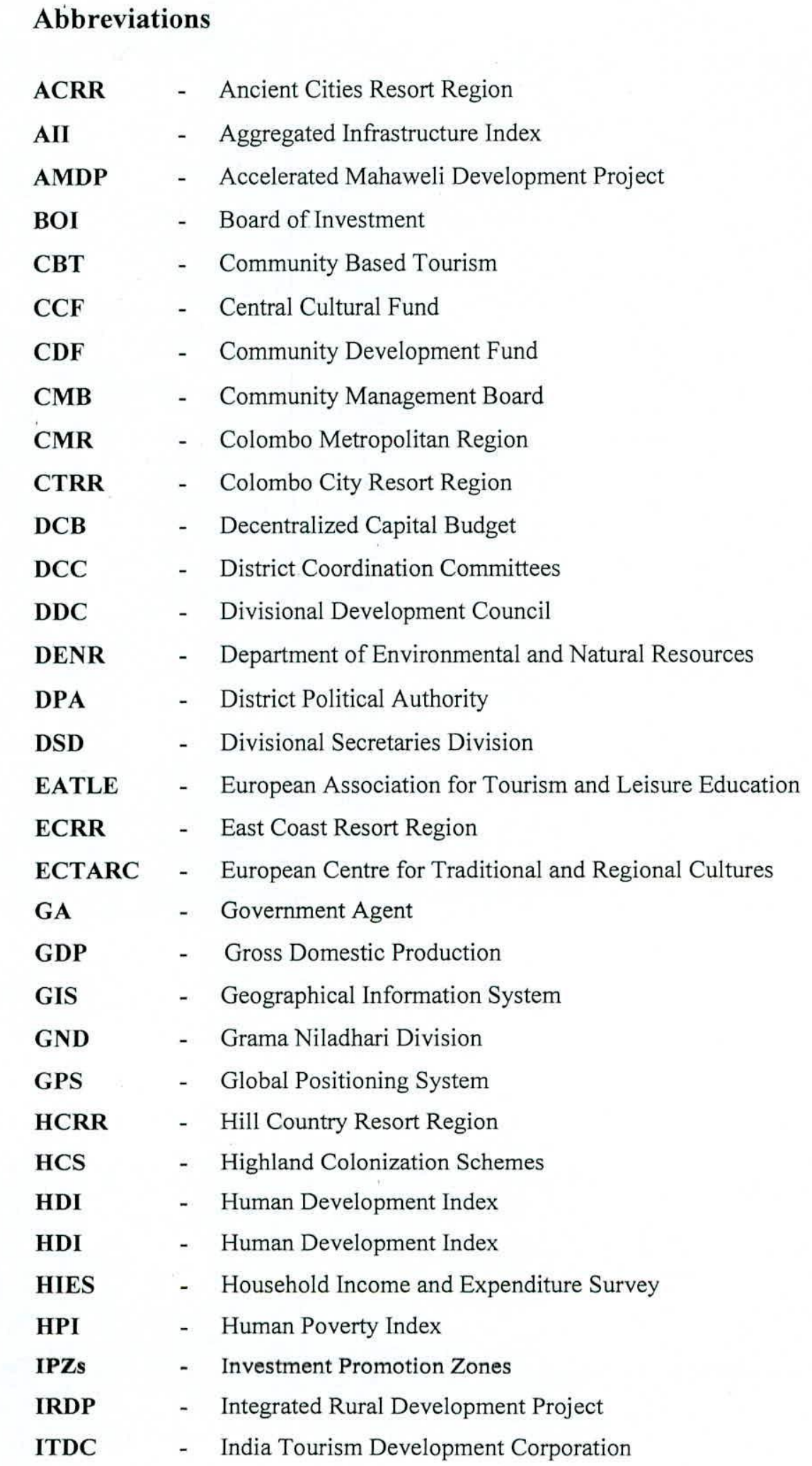




\begin{tabular}{|c|c|c|}
\hline IUCN & - & International Union for Conservation of Nature \\
\hline MPH & - & Multidimensional Poverty Headcount \\
\hline MPI & - & Mean / Median Monthly Per Capita Income \\
\hline MPI & - & Multidimensional Poverty Index \\
\hline NCP & - & North Central Province \\
\hline NUD-IST & - & Non-numerical Unstructured Data Indexing Searching and Theorizing) \\
\hline OECD & - & Organization for Economic Cooperation and Development \\
\hline PAWB & - & Protected Area and Wildlife Bureau \\
\hline PGDP & - & Provincial Gross Domestic Production \\
\hline REAP & - & Regional Economic Advancement Programme \\
\hline SATIDP & - & South Asia Tourism Infrastructure Development Project \\
\hline SLCB & - & Sri Lanka Convention Bureau \\
\hline SLITHM & - & Sri Lanka Institute of Tourism and Hospitality Management \\
\hline SLTB & - & Sri Lanka Tourist Board \\
\hline SLTDA & - & Sri Lanka Tourism Development Authority \\
\hline SLTPB & - & Sri Lanka Tourism Promotion Bureau \\
\hline UNDP & - & United Nation Development Programme \\
\hline UNESCO & - & United Nations Educational, Scientific and Cultural Organization \\
\hline VES & - & Village Extension Scheme \\
\hline WSCRR & - & West and South Coast Resort Region \\
\hline WTO & - & World Tourism Organization \\
\hline
\end{tabular}




\section{ACKNOWLDGEMENTS}

First and foremost, I would like to express my deep appreciation and gratitude to my supervisor, Professor (Emeritus) Y.A.D.S. Wanasinghe, who has played a remarkable role in enhancing my knowledge life in a more progressive way, providing constant encouragement, guidance and valuable advice. Without her encouragement, I would never have been able to complete this dissertation.

At the same time, I profoundly express my sincere gratitude to my co-supervisor, Professor T.M.S.P.K. Tennakoon for her patience, motivation, enthusiasm and immense knowledge. Her guidance helped me in my research and the writing of this thesis. Without her priceless support, this thesis would not have emerged in the present form.

With a great pleasure, I place on record my sincere and profound gratitude to Professor (Emeritus) M.M. Karunanayake and Professor M.D.C. Abhayaratne who remain in my memories forever, for their valuable advice.

I also express my thanks to Rev. Dr. Pinnawala Sangasumana, Professor C.K.M. Deheragoda, Professor R.M.K. Ratnayake, Dr. M.A.S. Wijesinghe and the remaining academic staff of the Department of Geography, who advised, guided and helped me during this period. 
I also take this opportunity to appreciate the contribution of Mrs. N.B. Hema Dharmawardene, Director General of the Ministry of Economic Development, who had always been supportive of my research activities in various ways.

I cannot forget to thank Mr. D.P.L. Walter Silva, former Director of Education who encouraged me giving his fullest support in editing this thesis. At the same time, I gratefully acknowledge the help of Mr. P.P. Hettiarachchi, former Director of Sri Lanka Tourist Board who advised me in various ways.

During the field work in the North Central Province, officers of government and non governmental institutions supported me to the best of their ability. I should specially thank the Divisional Secretaries and the staff off all the respective Divisional Secretariat Divisions. My grateful thanks go to the villagers in the area, including Mr. Karunadasa and Mr. Mahatun at Pemaduwa who provided me accommodation and transport facilities.

Throughout these difficult years, many of my friends and students helped me in various ways. Their support and care helped me to overcome setbacks and stay focused on my research. I greatly value their friendship, appreciating the support given. Dilini, Mahesha, Thilini and Irandi helped in editing the text of the thesis. Sunil, Shan, Rukshan, Anjana, Bandara, Bope and Malith provided relevant photographs. Savindri and Rajitha extended their support in editing and preparing the images. Anil and Udyashantha always supported me, when I needed their help. Viraj, Thissa, Sriyani, Niduka and Chamika translated questionnaires into various foreign languages. 
Finally, I take this opportunity to dedicate this thesis to my loving mother who sacrificed her whole life and soul to make success of my life. She always encouraged me, sharing my happiness and frustration. She tolerated my ignorance and looked after me with tears and a smile. I would never have successfully embarked on my life without her blessing, support and constant encouragement. 


\title{
An Analysis of the Role of Cultural Tourism on Regional Development of the North Central Province of Sri Lanka
}

By

\section{Hetti Arachchige Nishantha Hettiarachchi}

\begin{abstract}
Tourism is generally considered to be a positive agent in the economic and regional development process of developing countries. It is an economic activity that provides numerous opportunities for people in the peripheral regions in these countries to earn a living. It enables them to acquire wealth and stimulate their socio cultural and economic development. As the tourism sector accelerates the development of the other sectors too, it has the potential to solve the problems arising from inter and intra-regional disparities. Hence, the link between tourism and regional development has been recognized as a novel approach in the field of regional development studies. During the last few decades, many new forms of tourism have emerged in mass tourism and these have now been introduced as regional development strategies. Cultural tourism which is one of the above new forms is the fastest growing segment of the industry which can be used to accrue more benefits to peripheral regions where cultural and historical resources are abundant.
\end{abstract}

The main objective of this study was to analyze the present role and the potential contribution of cultural tourism to the development of the NCP. The secondary objectives of the study were to identify challenges to the development of the NCP; examine the extent to which cultural tourism has contributed to the regional development process of the region, identify the existing cultural tourist sites that attract tourists; discover untapped resources such as cultural activities; beliefs and customs in traditional villages that have the potential to promote cultural tourism; review the existing cultural tourism policies and strategies of xvii 
developing countries; using the experience gained in other developing countries, explore the benefits that have already accrued to the host communities in the region from cultural tourism; identify the current negative impacts of cultural tourism, and problems that would arise in future and recommend appropriate measures to weaken negative impacts and strengthen positive ones.

The methodology of this research comprised a number of steps; a) a preliminary survey to select the study area, b) a pilot survey to test questionnaires, c) data collection and d) data analysis. After a preliminary survey, Anuradhapura historic city, Mihintale and Tantirimale sacred cities and twenty nine traditional villages in the vicinity of the sacred sites were selected for the in-depth study using the judgment sampling technique. A thirty percent sample of host communities was selected from each village using the stratified random sample technique. The total sample selected for the survey was 480 , which comprised 290 villagers; 100 tourists; 30 hotel managers and 60 key informants. Given an exploratory nature to the research, various research techniques like, field and questionnaire surveys, interviews, observations and group discussions have been employed. Both quantitative and qualitative analytical methods were used in combination for analysis the collected data.

The overall findings of this research are that cultural tourism of the NCP has contributed to the development of the region playing a major role in generating employment opportunities and sources of income; development of agriculture and livelihood; empowerment of women; multiplier effects; infrastructure development and development of small and medium scale industries. The findings of this investigation can assist rural developers in the implementation of community development strategies based on women's empowerment.

Key words: Cultural Tourism, Regional Development, North Central Province xviii 